\title{
The Conceptualization of Risk Tolerance and Scale Development for Measuring Publics' Tolerance of Individual Health Risks
}

\author{
Hyoyeun Jun' ${ }^{1}$ and Yan Jin² (1)
}

1. Department of English, Communications and Media, Salve Regina University, Newport, RI, USA

2. Grady College of Journalism and Mass Communication, University of Georgia, Athens, GA, USA

\begin{abstract}
Risk tolerance, identified by scholars over two decades ago as an essential concept in risk communication, has remained understudied without clear conceptual and operational definitions. As the first study developing a multiple-item scale for measuring at-risk publics' tolerance of different risk types, this study refines the conceptualization of risk tolerance and advances its operationalization in the setting of individual health risks. Qualitative research (in-depth interviews: $n=28$; focus group: $n=30$ ) and two survey datasets (sample 1: $n=500$; sample 2: $n=500$ ) were employed for scale development and testing. Results identify that two types of individual health risk tolerance exhibited by at-risk publics: (1) Compulsive tendency toward risk taking (CTRT), as evidenced in their unwillingness to refrain from risky behaviors even if they know the negative consequences and (2) inertial resistance to risk prevention (IRRP), as indicated by their indifference toward or intentionally ignoring health messages advocating for behavioral changes. The two-factor 13-item scale's reliability, factorial structure, and validity are further assessed. This risk tolerance scale provides a valid and reliable psychometric tool for risk communication scholars and practitioners to measure publics' tolerance of different individual health risks in order to design effective messages to overcome it as a barrier.
\end{abstract}

KEYWORDS: risk, risk communication, risk tolerance, health risk, measurement, scale development

CONTACT Hyoyeun Jun (D) - E-mail: hyoyeun.jun@salve.edu • Salve Regina University • 100 Ochre Point Avenue • Newport, RI 02840, USA 
To strategize and execute more effective risk messages and emergency responses that motivate at-risk publics to take protective action is a critical task of risk communication scholars and practitioners (e.g., Heath et al., 1998; Heath \& Palenchar, 2000; Heath, Lee, \& Ni, 2009; Heath et al., 2019). When publics perceive a health risk from external threats, they perceive uncertainty, fear, and anxiety not only for the symptoms (and negative effects they are experiencing) but also for the causal factors that brought those symptoms (Aakko, 2004). Uncertainty has been defined as an individual's probabilistic belief (Dowling, 1986; Peter \& Tarpey, 1975), the adverse consequences of which was defined as the amount at stake in buying goals (Cox \& Rich, 1964) and the importance of loss (Taylor, 1974). Thus, to reduce felt uncertainty among at-risk publics and better fulfill health organizations' mission via purposeful use of risk communication as an integral part of strategic communication (Hallahan et al., 2007), risk communication practitioners need to be equipped with evidence-based knowledge of individual psychological barriers that prevent publics from taking preventative or protective actions.

Among psychological barriers limiting risk communication effectiveness, risk tolerance is a critical yet understudied one in the field of risk communication, thus a focal construct of this study. Risk tolerance first appeared in the literature of strategic communication over two decades ago (e.g., Heath et al., 1995; Nathan et al., 1992), positing that publics have different risk tolerance levels depending on the risk characteristics and individual differences. Thus far, however, we have only limited knowledge, with little empirical evidence, regarding risk tolerance and its effects in risk communication and management, as well as a lack of a systematically developed and tested measurement tool that directly captures risk tolerance itself as manifested in different risk situations (e.g., preventable individual health risks). To directly respond to these conceptual and measurement gaps associated with at-risk publics' risk tolerance and its impact on risk communication outcomes, this study focuses on explicating the concept of risk tolerance itself, in the context of individual health risk communication.

To do so, this study first reviews key concepts in risk communication and provides a refined conceptualization of risk tolerance, 
based on current literature in which similar concepts were used in understanding publics' risk perception and responses. Then, a scale for measuring individuals' risk tolerance is developed and tested using two survey datasets based on U.S. adult samples. With the established validity and reliability, this new risk tolerance scale has the potential to advance risk communication theory and provides an improved measurement tool for scholars and practitioners to gauge risk tolerance as a psychological barrier to behavioral change in order to overcome it via more effective risk communication efforts.

\section{Literature Review}

\section{Risk and Risk Perception}

Risk, mostly from a health communication perspective, is generally described as the threat potential for injury, disease, and even death under certain circumstances (e.g., Chen, 2018; Gaube et al., 2019; Hunter \& Fewtrell, 2001). Risk is defined as societal common belief of the perception of the possibility of a negative event (S. Venette, 2008; S. J. Venette, 2003). One of the ways to understand how a potential for a specific event is perceived as a risk is dependent on the convergence between control and dread (Slovic, 1987). For instance, when people perceive a certain risk as "voluntary," they also tend to judge that risk as "controllable." On the other hand, when a risk is perceived as "dread" risk, there is a lack of controllability and unfair distribution of risks and benefits (Slovic, 1987). Nuclear weapons and nuclear power were referred as examples of high dread risk (Slovic, 1987). Through communicating risk, publics could estimate their own level of control and dread, the decision of which can affect how much they willingly tolerate that risk. Risk communication, centering on the dissemination of risk information to at-risk populations, takes place in a variety of situations, from product harms to national crises such as Three Mile Island (V. T. Covello et al., 1988). When a risk is communicated by governmental officials, expert and/or laypeople (V. T. Covello et al., 1988), individuals who receive such risk information start their own process of perceiving the risk itself. 
At-risk publics, a concept used by scholars in health risk communication and disaster communication (e.g., Bean et al., 2015; Liu et al., 2017), refers to any individual or groups of individuals who are exposed to or potentially facing a preventable risk that is directly threatening their own health, safety, and/or well-being; if they choose to tolerate the risk (by not taking preventive actions), they are likely to face the negative consequences of the risk in the future. For example, in the context of getting human papillomavirus (HPV) as a preventable health risk, at-risk publics can include all sexually-active young adults who have not received an HPV vaccine; if they choose to tolerate this risk (i.e., postpone receiving the HPV vaccine as a preventative measure), they could potentially get HPV infection and face unhealthy consequences as a result.

Perceived risk, from the perspective of at-risk publics, has been conceptualized into two dimensions: uncertainty and adverse consequences (e.g., Bauer, 1960; Chen, 2018; Dowling, 1986). Individuals' process of perceiving a risk is multidimensional, influenced by different factors including trust, voluntariness, controllability, familiarity, benefits, catastrophic potential, and uncertainty in relation to a given risk (Covello, 2008; Gaube et al., 2019; Paek \& Hove, 2017). This also can be explained by "control" and "dread" people perceive from each specific risk (Slovic, 1987). How much control and dread people have toward a risk can influence how they perceive that risk. Furthermore, individuals tend to experience different levels of fear, worry, anxiety, or anger, depending on how they perceive and judge these factors (Covello, 2008). A prior study found that there is a greater level of media coverage for "dread" risk compared to "controllable" risk (Slovic, 1987). Thus, at-risk publics could depend more on their media consumption to decide their coping strategies for a "dread" risk compared to a "controllable" risk. As individuals perceive and feel these influencing factors differently, they tend to perceive the risk itself differently and thereafter enact different risk responses (Covello, 2008), which sheds light on: (1) why some risks end up inducing more extreme responses than others and (2) why some risks are more tolerated than others.

In the context of medical hazards, Slovic and his colleagues (1989) suggested risk (e.g., seriousness of harm) and warning (e.g., 
newness) as two factors of risk perception. This is also applicable in understanding individuals' tolerance or avoidance of nuclear power plants and nuclear waste repository (Groothuis \& Miller, 1994; Slovic, 1992). For instance, publics perceived a nuclear waste repository more negatively compared to a nuclear power plant (Slovic, 1992). Slovic (1992) also suggested locating a risk in the perspective of interrelationship of "Unknown Risk" and "Dread Risk" (p. 123). As an example, the public perceived nuclear weapon fallout as both a high "Unknown Risk" and a high "Dread Risk" (Slovic, 1992).

Furthermore, individuals tend to judge relatively unknown risks as more uncertain compared to those that are well-known (Covello, 2008). Rooted in the expectancy model, individuals are likely to have higher motivation to change their behavior when they believe (with perceived high probabilities) that their effort put in behavioral change can bring positive outcomes (Fishbein \& Ajzen, 1975). Therefore, to be more effective in motivating at-risk publics for behavioral change, risk communication practitioners need to gauge, with enhanced accuracy, the level of probabilities at-risk publics believe in terms of the positive outcome should they decide to take risk-prevention measures.

\section{Earlier Definitions of Risk Tolerance}

Over two decades ago, Nathan and colleagues (1992) posited that individuals have different risk tolerance level depending on the risk characteristics and individual differences. According to Heath and his colleagues (1995), whether an individual is to tolerate a risk or not is determined by whether one perceives benefits over risks in a given situation. The limited empirical evidence as associated to risk tolerance in strategic communication suggests: (1) lower level of risk tolerance seems to be correlated with higher perceived risk (Heath et al., 1995; Nathan et al., 1992) and (2) individuals with low risk tolerance are likely to perceive the source of risk as more harmful than those who tolerate risk more. However, what is risk tolerance itself, or in other words, what indicates the level or degree of an individual's risk tolerance, remains unknown. Recently, Slovic (2016) called for more studies on at-risk publics' "tolerance of risk" (p. 25), which might hold the key to a fuller 
understanding of the mechanisms beneath the observed differences in risk perception and responses as well as to filling in the knowledge gap regarding uncertainty (Liu et al., 2016) in the larger domain of strategic communication research and practice.

There are several challenges that need to be addressed as scholars delve into improving the conceptual and operational definitions of risk tolerance. First, the multidimensional nature and relational aspects of risk tolerance need to be emphasized in the theorizing process, as advocated in the earlier work of Baird and his colleagues (e.g., Baird, 1986; Baird et al., 1987). Regarding the relationship between risk voluntariness and risk tolerance, for instance, Baird (1986) found that, compared to an involuntary risk, individuals perceived a voluntary risk as more tolerable. Also reported by Baird (1986) was that risk tolerance was correlated to a variety of attitudinal and demographic variables (e.g., perceived benefit, immunity to the risk, costs in risk control, number of years individuals lived in the community). Second, the distinction between the concept of risk tolerance itself and the determinants that lead or correlate to varied risk tolerance level needs to be clearly made. For example, in studying risk tolerance in the context of regarding air pollution as an environmental health risk, Baird (1986) did not directly measure risk tolerance itself but postulated other determinants instead that correlated with risk tolerance (e.g., risk voluntariness or perceived benefit and harm). Therefore, a clear definition of risk tolerance itself (not its determinants) and its direct measure (capturing how risk tolerance manifests itself in different observable ways) are essential to further theorizing risk tolerance.

In sum, these pioneering works on risk tolerance (including other relevant concepts and its determinants) and the earlier empirical evidence have shed light on the direction of further explicating risk tolerance in health risk context. First, risk tolerance is a multidimensional construct (Baird, 1986; Baird et al., 1987). Second, although a relational approach to the understanding of the formation of risk tolerance is relational (influenced by risk perception and factors contributing to different risk perceptions) (e.g., Covello, 2008), the examination of which factors influence one's decision to tolerate a risk (or not), based on benefit/risk 
perception, is not a direct measure of risk tolerance itself. Previous approach to risk tolerance (i.e., focusing on identifying factors that lead to varied risk tolerance) does not provide explanation when individuals choose to tolerate a risk despite the fact that they are aware of the greater benefit of following risk-prevention recommendations. Furthermore, although the existing operationalization of risk tolerance helps measure the surroundings of risk tolerance, it provides no direct measure of the attributes of the construct itself (e.g., the degree or likelihood an individual is or is not willing to tolerate a specific risk). Additionally, individuals do not perceive risk and benefit symmetrically (Sjöberg \& DrottzSjöberg, 2001). For instance, compared to those who perceived the benefits of having a nuclear waste repository, people who had the desire to avoid the risk itself exhibited much stronger motivation for taking actions accordingly (Groothuis \& Miller, 1994).

Therefore, a refined conceptualization and an improved scale that specifically measures risk tolerance itself, rather than assuming the level of risk tolerance through perceived benefit and risk, is necessary. The following sections further delineate: (1) our proposed conceptualization of at-risk publics' risk tolerance in the context of preventable health risks, and (2) a multiphase empirical study through which a multidimensional scale, directly measuring individuals' risk tolerance, was developed and tested.

\section{Conceptualization of Risk Tolerance}

Risk communication contributes to the well-being of individuals and communities (Heath \& Abel, 1996). To inform publics with accurate risk information and motivate them for protective action taking, health organizations and emergency response services need to understand how publics perceive risks differently and what communication barriers they need to overcome. As Haukenes (2004) pointed out, risk is difficult to explain and new approaches to risk communication are needed to identify new dimensions of risk perception and uncover hidden barriers that complicate the relationship between risk perception and health/ safety-related behaviors (Rudisill, 2013). Risk tolerance is one of 
the hidden barriers, the conceptualization and operationalization of which is yet to be fully examined.

Ever since the pioneering work on risk tolerance (Nathan et al., 1992; Heath et al., 1995), which primarily focused on environmental health risks, little theoretical or empirical advancement has been made regarding risk tolerance in the strategic communication discipline. To extend the existing risk tolerance research and extend its scope and application to different risk communication areas, we start the process of explicating risk tolerance with conceptualizing it in the context of risk communication, drawing evidence-based insights and inspirations from other social scientific disciplines.

\section{Risk Tolerance Emerged from a Multidisciplinary Tapestry}

The concept of "tolerance" is rooted in a rich multidisciplinary soil, nourished by studies in education, project management, financial planning, and economics. In the field of education, tolerance is defined as the opposite concept of discrimination, which let people act against ones that they dislike and disagree with (Vogt, 1997). On the contrary of discrimination, tolerance requires self-control and involves support for others' rights even though the others are people whom they dislike or have a negative attitude toward (Vogt, 1997). Individuals' tolerance level can be predicted by personality traits, religious guidance, and age, as well as influenced by education (Vogt, 1997). Tolerance is strongly associated with negative emotions, as a core of tolerance lies in overcoming disliking a particular subject (Vogt, 1997). Therefore, we expect that when at-risk publics tolerate a risk (e.g., individual health risk), they are likely to perceive the negative effects of those risks and may consequently experience certain negative discrete emotions.

In the field of project management, risk tolerance of a project (project risk tolerance) is considered as a changing variable throughout the life of a project, with a firm, a project manager, and/or stakeholders as decision makers for tolerating a project risk or not (Kwak \& LaPlace, 2005). This definition emphasizes the dynamics of key players that jointly trigger risk tolerance, which suggests that, in the context of risk communication, organizations 
and at-risk publics are likely to interact and co-shape the level of individuals' risk tolerance.

Financial planning literature has defined risk tolerance as how much one is willing to engage in behaviors that can cause uncertain outcome with possible negative outcome (Irwin, 1993). In the literature of economics, risk acceptability, a concept similar to risk tolerance, is decided according to a simple cost-benefit analysis, which means that a risk is acceptable if the economic savings arisen out of action to reduce a risk outweigh the cost of such action (Hunter \& Fewtrell, 2001). These benefit/risk decisionmaking approaches align with strategic communication scholars' argument that publics perceive benefits over risks to decide whether to tolerate a risk or not (Heath et al., 1995). These findings also shed light to the expectation that at-risk publics are more likely to tolerate a risk when their perceived risk uncertainty is low.

Based on how the above multidisciplinary research has defined risk tolerance, we posit that, in the context of risk communication, risk tolerance is manifested as at-risk publics' level of tolerance toward an emergent or existing issue containing risks if not responded to as instructed.

\section{Risk Tolerance as Unwillingness to Overcome a Preventable Risk}

To clearly define risk tolerance, it is necessary to first differentiate it from other similar yet distinct concepts (e.g., risk taking, acceptable risk, risk acceptance). Scholars have conceptualized publics' predisposition for risk-taking tendency as an engagement in behaviors acknowledging the risk's likelihood of a punishment or a reward loss (Ferguson et al., 1991). Laypeople's tolerating attitudes were found to be influenced by qualitative factors including not only fatality information but also familiarity, voluntariness, controllability, fairness, acuteness, time and space, and individual mitigation (Covello, 1983; Fischhoff et al., 1978).

Risk communication scholars further studied how individuals might be "accepting" and/or "avoiding" a risk. On one hand, risk literature has explored the concept of acceptable risk at an individual level, which depends on the perceived level of voluntariness, 
ability to escape with precautions, familiarity, natural causes, shortterm influence, and understanding of science (Bennett, 1999). Starr (1969) and Baird (1986) found that people tended to accept risks more when they perceived benefits from activities involving risks for both technological and environmental health risks. Risk acceptability was further discussed independently regarding each specific risk, depending on the cause of risk topic (natural or man-made) (Fell, 1994). Risk acceptability, on the other hand, is a concept developed at community/group level and described in a disease burden approach, amounting to how much total burden of disease (as a health risk) a certain community can take (Hunter \& Fewtrell, 2001).

These previous studies on risk taking, acceptable risk, and/ or risk acceptance, regardless of the unit of measurement, have focused more on which characteristics in a risk motivate people to accept the risk more. These concepts, however, do not necessarily reflect the fact that, in many risk situations (e.g., individual health risks), at-risk publics know about what the risk is and what the alternatives are to overcome the risk (e.g., following recommended risk-prevention actions) (Tchiehe \& Gauthier, 2017). Additionally, while accepting a risk means that after doing cost-benefit analysis the risk would be fully taken into the decision maker (Baird, 1986; Starr, 1969), tolerating a risk does not always mean that the risk is fully taken by oneself. The latter pertains more to observed behaviors of postponing following recommended risk-prevention behaviors or deliberately ignoring such instructions, driven by one's unwillingness to overcome a preventable risk. Ignoring recommended behaviors can grow into habitual inertia, which can motivate people to keep their old behavior (Covello \& Sandman, 2001). At the individual level, this type of inertia in people can explain how and why people are tolerating a risk, even though they know what to do to prevent the risk from harming themselves. Inertia can also be found at the institutional level, resulting in resistance to policy change regarding public environmental risk (Harries \& Penning-Rowsell, 2011). Therefore, given the main conceptual difference between the existing risk-taking and/or risk-accepting concepts in previous literature and the risk tolerance concept this study posits, the current study focuses on risk 
tolerance by exploring individuals' risk tolerance, or their unwillingness to overcome a preventable risk, as formed through different psychological processes such as inertia (e.g., habitually falling back to existing risky behaviors) or the opposite force (e.g., compulsively driven forward to resist behavioral changes), grounded in Covello and Sandman's (2001) framework.

Another concept relevant to risk tolerance is risk bearing (Fama, 1980; Kasperson \& Palmlund, 1989; Waymer \& Heath, 2015), which is agency (e.g., organizations, companies, and entities) focused. The essence of risk bearing lies in that: (1) risk bearers have a role of their own in taking a risk of uncertainty (e.g., a nuclear plant as an organization chooses to bear a risk that could affect itself) and (2) if things go wrong, risk bearers accept the losses of their own. As Coombs and colleagues (2019) pointed out, one of the purposes of risk communication is to achieve more effective communication between different risk bearers suffering from risk outcomes and/or risk generators (e.g., organizations whose business unavoidably generate risks, and publics who can be affected by risk consequences). For instance, at the organizational level, a company may need to choose whether to bear certain risk of losses if the risk would happen or to avoid the risk in advance by taking risk-prevention action (e.g., investing in prevention through insurance). Therefore, it is important for a risk-generating risk bearer (e.g., chemical companies) to plan and implement strategic risk communication mindfully so as to optimize the risk tolerance among other groups of risk bearers that are under the threat of potential risk outcomes (e.g., people who are living near the chemical plants) (Heath \& O'Hair, 2009).

More recently, according to Brady (2012), most social science risk perception research has focused on either "what characteristics of a risk increase or decrease its perceived risk by members of the public" or "what are the characteristics of individuals perceiving a risk that lead some people to perceive risks differently from others" (p. 548). Risk acceptability literature, for example, tends to focus more on the uncertain nature or characteristics of a risk itself (Kentel \& Aral, 2007). More research is needed to examine what psychological processes and individual characteristics contribute to differed perception of and response to the same risk. As 
Eastin et al. (2015) advocated, risk communication scholars need to examine different decision-making stages among at-risk individuals, including those who have decided to act and those who have decided not to act.

Therefore, by shifting the focus from the characteristics of a risk itself to the characteristics of individuals who tolerate the same risk differently (Brady, 2012; Eastin et al., 2015), the concept of risk tolerance helps gauge how at-risk publics cope with a risk as evidenced in how much tolerance of a risk they are willing to take by not overcoming a preventable risk. Furthermore, this study focuses on refining the conceptual and operational definitions of risk tolerance in the context of individual health risks, which echoes the urgent need of more effective public health communication about preventable health risks. According to the U.S. Department of Health and Human Services (U.S. HHS), preventable health risks are risks that can be prevented (e.g., one course of the birth defects, as a health risk, can be contributed by alcohol use during pregnancy, which is preventable by avoiding using alcohol) (U.S. HHS, 2000). Under this overarching umbrella, the conceptualization and scale development of risk tolerance in current study can be applied to any preventable health risk settings, in which at-risk publics are: (1) are aware of how to reduce a preventable risk and (2) have access to risk-prevention instructions, but (3) intentionally neglect following recommended behavior to avoid, reduce, or adverse the risk itself.

As Bennett (1999) argued, whether a risk is acceptable or not depends on how much voluntariness there is for the risk and if an individual has the ability to escape from such risk with precautions. In a similar vein, yet focusing on the uniqueness of what risk tolerance intends to capture as an individual psychological barrier for changing risky behavior, we define risk tolerance as at-risk publics' degree of unwillingness to overcome a preventable risk that threatens their own health, safety, and/or well-being. Grounded in Covello and Sandman's (2001) framework, it is manifested in their individual behaviors of: (1) habitually falling back to existing risky behaviors sustaining risky behaviors (e.g., displayed indifference toward or intentionally ignoring health messages advocating for behavioral changes) or (2) compulsively driven forward to resist 
behavioral changes (i.e., exhibited unwillingness to refrain from risky behaviors even if they know the negative consequences). We further posit that individuals' decisions on whether to tolerate a preventable risk (or not) can determine whether (and if so, to what degree) certain risky behavior change is either enabled or inhibited at individual level.

\section{Gauging Risk Tolerance in Individual Health Risk Communication}

When and why people seek information regarding potential negative consequences of an action in the context of environmental, health, and natural disasters are among the most important research questions for risk communication scholars (Griffin et al., 1999; Kahlor, 2010). Brady (2012) posited two types of risk with different perceived level of control: (1) individual health risks over which individuals have perceived control and (2) disasters over which individuals have little or no perceived control. Publics' risk perception about specific risk topics also vary according to personal and societal factors (Krewski et al., 2012).

In addition, according to the probability and impact matrix by the Office of Government Commerce (OGC), project risk tolerance is the highest when there is high probability of inherence risk and low resulting impact, while project risk tolerance is the lowest when the resulting impact is higher with the medium level of probability (OGC, 2001). Similar to how Bennett's (1999) study on public health risks, risks assessed from project management were tolerated more when it was more inherent. Therefore, it posits the possibility that individuals might tolerate different risks with varied degrees, depending on whether the risks are more inherent (e.g., individual health risks) and level of risk controllability as perceived by individuals. Therefore, due to the change of tolerance level depending on other risk factors, such as inherence and controllability, the measurement for risk tolerance can reflect this state-based aspect of risk tolerance. To extend the application of risk tolerance to public health crisis management, for example, during the pre-crisis stage (Reynolds \& Seeger, 2005) or before any prominent crisis happens in a community, if health 
communication practitioners need to gauge the existing level of health risk tolerance among members of the at-risk community, risk tolerance level, about a specific risk topic or issue, can be used as a trait-based measure.

Taking these scholarly concerns into consideration, in this study, we focus our first attempt to advance risk tolerance measurement on the front of individual health risks, more inherent risks (Bennett, 1999) over which individuals have perceived control (Brady, 2012). By so doing, we aim to: (1) have a focal risk context for scale development and (2) provide context-specific recommendations for health communication practitioners to design more effective health risk messages that help reduce uncertainty (Reynolds \& Seeger, 2005). Additionally, public health information officers can use the risk tolerance scale to gauge their at-risk publics' risk tolerance level regarding specific health issues and then utilize such knowledge to tailor health information design and dissemination, especially via the use of local health agenda and resources (Avery, 2019). The scale will equip practitioners with a valid and reliable measurement tool to identify and then overcome hidden barriers (e.g., risk tolerance) in order to motivate at-risk publics' behavioral change toward improved life.

\section{Methods and Risk Tolerance Scale Development}

\section{Initial Items: Generation and Procedures}

To generate initial items that ensure the content validity of the risk tolerance scale in the context of individual health risks, we conducted a qualitative study to explore how individuals describe their own experience of tolerating a health risk that threatens their own health and well-being. A total of 28 in-depth interviews with non-student adults in the U.S. and a focus group of 30 college students enrolled at a large Southeastern university in the U.S. were conducted, aiming at capturing the actual descriptors of how people tolerate health risks (i.e., unwillingness to modify their risky behavior, even when they are aware of the benefits of overcoming preventable risks by following recommended actions). The same set of open-ended questions were asked in both the focus group and in-depth interviews to explore: 
1. how participants tolerated preventable risks (as defined by the researchers) according to their own direct experiences;

2. any emotions they felt during their risk-tolerating processes;

3. their experiences of ignoring any health messages regarding recommended behavior;

4. what triggered them not to follow the recommended behavior; and

5. what could help reduce their risk tolerance.

The example questions from these in-depth interviews and focus groups include: "Have you ignored any health messages regarding the recommended healthy behavior? If so, please describe your experience" and "Have you intentionally tolerated any type of health risks or technological risks? Is there any type of risks that you wanted to tolerate more? If so, please share any example" and so forth.

The transcripts from both focus group discussion and interview were then analyzed, following the qualitative data analysis guidelines recommended by Lindlof and Taylor (2017). The qualitative data were initially reduced during qualitative coding by removing irrelevant information. Data were then reorganized and merged into common themes. The last stage (conclusion drawing and verification) involved identifying and interpreting categories and patterns. As the key step for ensuring content validity of a new scale, we extracted any relevant (or likely-to-be relevant) indicators and statements, rendered in participants' own wording and based on their vivid descriptions. Throughout the process, asmany-as-possible items likely displaying or exhibiting individuals' risk tolerance, capturing different aspects of risk tolerance as a construct, were identified and organized in the form of individual statements, ready to be incorporated into a survey instrument. As a result, a total of 53 items were generated as the initial pool of risk tolerance items, in the form of 53 statements (i.e., 53 different indicators manifesting how an individual health risk is being tolerated) to be further assessed for further consideration in the risk tolerance scale (see Appendix A). 
Next, two online survey data sets were collected using Qualtrics survey panels among U.S. adults (Sample 1: $n=500$; Sample 2: $n=500$ ) from February to May in 2019. At the beginning of the survey questionnaire, the definition of "risk" in the general context of individual health risk was provided. Participants were then instructed to think of a health risk that fits into all three criteria: (1) "You are aware of and concerned about it personally"; (2) "You know that there are ways to overcome the danger of this health risk by modifying your behavior (e.g., stop doing certain things or taking actions recommended by your doctor)"; (3) "Nevertheless, you choose to tolerate this health risk by ignoring or refusing to follow recommended behaviors." After reading this instruction, participants were asked to respond to each of the 53 survey items, each representing one of the 53 risk tolerance items generated in the prior qualitative phase. Participants' assessments of their agreement with each item, regarding their own tolerating of the specific health risk they individually focused in mind, were measured using a 7-point Likert-type scale ranging from 1 (strongly disagree) to 7 (strongly agree). Aiming to develop a scale assessing individuals' tolerance of risks across different risk types and contexts, the above approach (i.e., instructing individual participants to choose and focus on one specific risk they each have been tolerating, instead of providing a specific risk context for them) was chosen, adopting a similar approach taken by Cornia et al. (2016) in capturing differences in disaster management from different cultural contexts.

\section{Item Reduction and Reliability Testing}

Survey Sample $1(n=500)$ was used for item reduction and exploratory factor analysis (EFA). We first checked to see if there was any item (1) with low correlation with other items and/or (2) without normal distribution (e.g., highly skewed distribution) (Clark \& Watson, 1995). No item was sorted out through this process. As a result, all 53 items remained for the next step of item reduction.

Item reduction. For the next step, principal component analysis (PCA) with Promax rotation was chosen due to its advantage of being fast and good at presenting in a conceptually simple way 
(Abdi \& Williams, 2010; Hendrickson \& White, 1964). This initial step in data analysis (using all 53 items) returned six components with initial eigenvalues greater than 1 (explaining $65.96 \%$ of the variance). To test the appropriateness of factor analysis, the KaiserMeyer-Olkin (KMO) test of sampling adequacy and the Bartlett test of sphericity were used (Kaiser \& Rice, 1974). Our data indicated the KMO level of .97 and the significance of the Bartlett test (.oo).

During this process, we first checked whether there was any item with factor loadings less than .40 (Tabachnick et al., 2007). None of the items was in the above criterion, which led to dropping zero items from this step. Then a total of 16 items with communality value less than .50 were identified and eliminated (Meyers et al., 2013). Last, we checked whether any of the remaining items cross-loaded in more than one component with factor loadings more than .50 (Richman, 1988; Tabachnick et al., 2007), which led to the elimination of another 24 items. As a result, a total of 13 items remained in the risk tolerance inventory after the above item reduction series.

Exploratory factor analysis. Taking into consideration that the possible factors of risk tolerance themselves may be correlated (Comrey, 1988) as posited earlier in our conceptualization, a Principal Axis Factoring with Promax Rotation (used when correlation between factors are expected theoretically) was performed next on the remaining 13 risk tolerance items. As a result, two factors and 13 items were rendered as the recommended structure and items for measuring risk tolerance. The two-factor solution corresponded well with the conceptualization of risk tolerance as manifested in individuals' behaviors of (1) habitually falling back to existing risky behaviors sustaining risky behaviors (e.g., displayed indifference toward or intentionally ignoring health messages advocating for behavioral changes) or (2) compulsively driven forward to resist behavioral changes (i.e., exhibited unwillingness to refrain from risky behaviors even if they know the negative consequences. Factor loadings from this final step of EFA for the 13 items are presented in Table 1. 
TABLE 1 Structural Analysis of Risk Tolerance Inventory Items

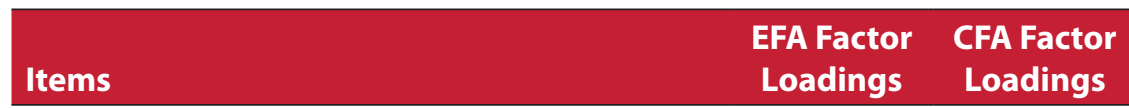

Factor 1:

Compulsive Tendency toward Risk Taking (CTRT)

I did it anyways, even though I knew it was an

0.77

0.70

unhealthy choice

I know that what I chose is not a smart decision,

0.80

0.71

and it is not healthy, but I had to pursue it

There is a risk in my choice, but I am willing to

0.83

take that risk, even though it is not really good

for myself

Even though I know the risk of doing what I do,

0.85

I would still do it

Even though I know what I do is bad, I cannot

0.77

0.75

give it up

I know what I am doing is bad and harmful, but

0.84

I do not take actions to change

I choose to indulge despite knowing this choice

0.82

0.72

is bad for me

When I receive the health message to pursue

0.70

0.64 the recommended behavior, I willingly take the risk and tell myself that "I will eventually do that"

\section{Factor 2: \\ Inertial Resistance to Risk Prevention (IRRP)}

I ignore the risks that are described in the

0.76

0.79

health messages

I did not really care that much about the effects

0.73

0.71

of risks I am taking

If I read the recommended health message, I would feel disinterested, because I know I will

0.79

not modify my behavior

If I read the recommended health message, I

0.74

0.70

would feel insensitive, because I know I will not modify my behavior

I am going to choose this less healthy behavior regardless 
Factor 1 is labeled "Compulsive Tendency toward Risk Taking (CTRT)" ( $M=4.12$; SD = 1.79), including eight items describing individuals taking the risky choice even if they are aware of the risks and the better options for their health $(\alpha=.90)$, together capturing exhibited unwillingness to refrain from risky behaviors even if they know the negative consequences. Factor 2 is labeled as "Inertial Resistance to Risk Prevention (IRRP)" $(M=3.38 ; S D=$ 1.68), including five items describing individuals ignoring health messages and feeling disinterested when they read health messages $(\alpha=.88)$, together capturing displayed indifference toward or intentionally ignoring health messages advocating for behavioral changes. Each subscale for Factor 1 and Factor 2 showed a high level of internal consistency. With these indicators from EFA, this two-factor 13-item instrument was presented for the next step scale test: confirmatory factor analysis (CFA).

\section{Confirmatory Factor Analysis}

Survey sample $2(n=500)$ was used for confirmatory factor analysis (CFA). To check the factor structure, CFA was performed using AMOS 23 with a 13-item oblique model to test the hypothesized factor structure from EFA. The oblique rotation, allowing for correlation between factors (Tabachnick et al., 2007), was selected due to the theoretical assumption that the dimensions of risk tolerance are likely to be correlated (e.g., Baird, 1986; Baird et al., 1987). This assumption was further verified by the significant correlation between the two factors according to their structures yielded during the EFA $(r=.75, p \leq .001)$. Factor loadings from CFA for the 13 items are presented also in Table 1 . Full descriptive statistics of all 13 items are included in Table 2, with a high internal consistency $(\alpha=.94)$. 


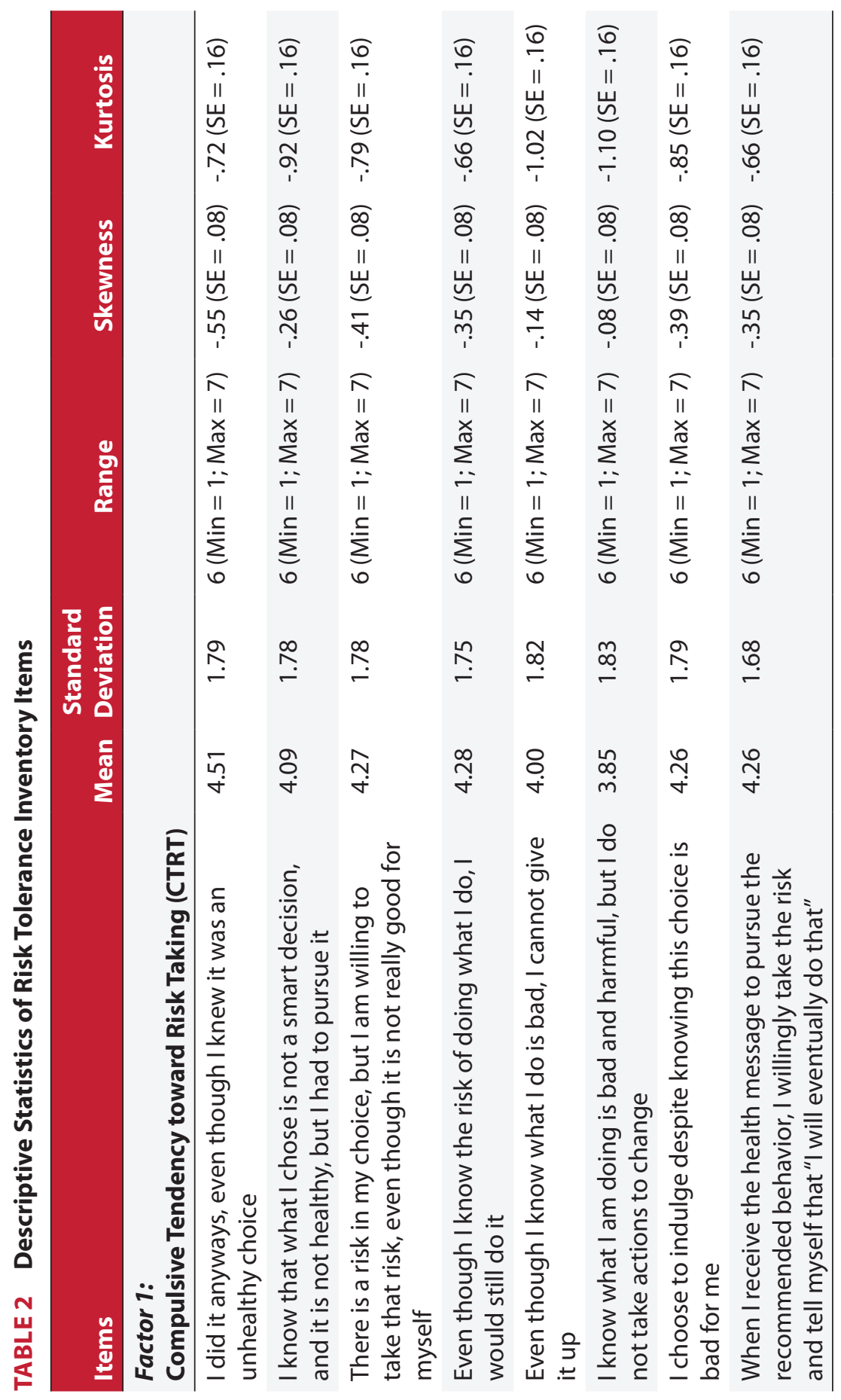




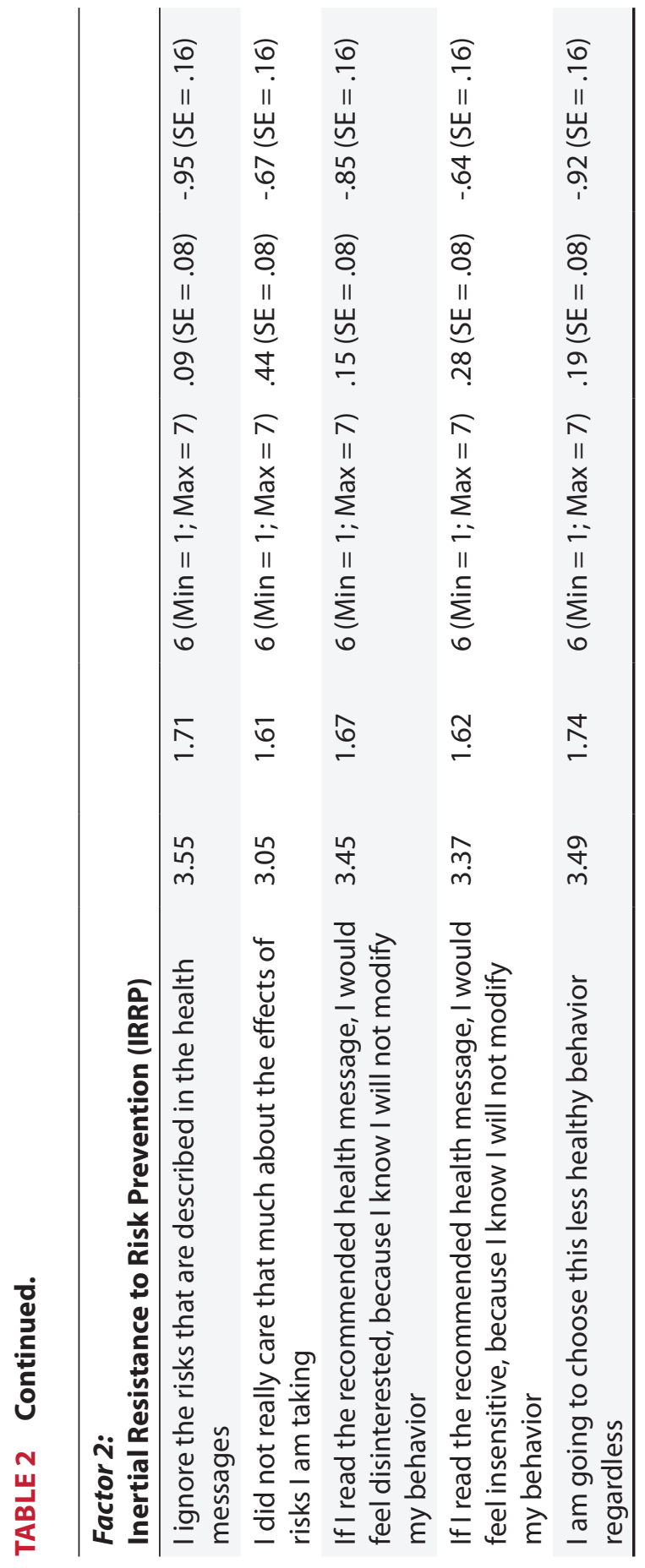


According to our CFA results, the combination of several goodness-of-fit indices demonstrated a reasonable overall fit of our estimated two-factor oblique model to the observed data, $x^{2}(60$, $N=500)=334.91, \mathrm{p} \leq .001(\mathrm{RMSEA}=.09 ; \mathrm{CFI}=.93$; AGFI = .91; GFI $=1.0$ ). Thus, based on the conceptualization of risk tolerance and through both qualitative and quantitative methods, a twofactor, 13-item inventory for measuring at-risk publics' tolerance of preventable individual health risks, using the Likert scale, was generated and recommended (see Appendix B).

\section{Discussion}

Strategic communication researchers have offered guidance on what, how, and when to communicate risk information (Janoske et al., 2013) as well as opportunities of advancing risk theory and demonstrating the value of strategic risk communication to senior leadership in the process of risk crisis communication (Liu \& Pompper, 2012). How to inform publics about risk information, when there is a high degree of uncertainty, is still lacking (Liu et al., 2016). Essential to the quest for "knowing the uncertainty" lies with the understanding of risk tolerance, an understated psychological barrier that prohibits at risk-publics from taking risk-aversion actions for their own well-being. A further enriched conceptual and empirical foundation is needed to allow scholars and practitioners to gain more insights on how individuals cope with risk-induced uncertainty and how their risk tolerance is manifested, based on which more effective risk communication strategies may be developed.

To echo this research gap, our study took an important step toward explicating risk tolerance in risk communication by providing a refined conceptualization from multidisciplinary literature. This study is also the first in the field of risk communication to develop a scale for measuring risk tolerance of individual health risks via multi-methods (in-depth interviews, focus group, and survey datasets) and statistical procedures of psychometrics, which advances the risk tolerance theories (Slovic, 2016) at the measurement level. 
In the general context of individual health risks, the scale we developed provides empirical evidence that risk tolerance can be measured by observing at-risk individuals' behaviors of (1) habitually falling back to existing risky behaviors sustaining risky behaviors (e.g., displayed indifference toward or intentionally ignoring health messages advocating for behavioral changes) or (2) compulsively driven forward to resist behavioral changes (i.e., exhibited unwillingness to refrain from risky behaviors even if they know the negative consequences). Our study advances the theory and practice in understanding why and how people ignore recommended behaviors (Covello \& Sandman, 2001) and in continuing to unearth hidden psychological forces (e.g., Chen, 2018; Paek \& Hove, 2017) that can motivate at-risk publics to tolerate serious yet preventable individual health risks.

\section{How Individuals Tolerate Preventable Individual Health Risks}

To solve the puzzle why people do not follow recommended behaviors to reduce preventable risks, this study conceptualizes and defines risk tolerance as at-risk publics' degree of unwillingness to overcome a preventable risk, which is proposed to be manifested in individual behaviors of sustaining risky behaviors and/or resistance to follow recommended risk-aversion actions. Focusing on individual health risk as the risk type over which individuals have control (Brady, 2012), this study develops a scale with two factors and a total of 13 items for measuring individuals' risk tolerance (unwillingness to change risky behavior) in a health risk setting.

Prior risk communication research has predominantly focused on people's willingness to engage in risky decision-making, which is measured by risk-taking orientation (Weber et al., 2002), or risk-taking (Ramon, 2009), which is measured based on people's tendency to engage in behaviors that can have risk of injury, illness, and disease (Rook et al., 1990). However, these measurements for risk-taking orientation heavily rely on presenting the risky tendency itself without further identifying the varied patterns underneath individuals' taking or avoiding of a specific risk. For instance, one person can have low risk tolerance for flu, therefore getting flu vaccination every year; in the meantime, the same 
person can have high risk tolerance for smoking-related health risks and never even considered quitting smoking cigarettes. To unearth the complex psychological process the individual enacts in facing different health risks, this new risk tolerance scale not only captures the status of people tolerating risk while being aware of what to do instead, but also provides a multi-item tool to assess the degree of tolerance (unwillingness to change) individuals might have for different health risks.

Furthermore, the two factors rendered in our scale development processes, Compulsive Tendency toward Risk Taking (CTRT) and Inertial Resistance to Risk Prevention (IRRP), shed light on two interconnected risk tolerance patterns with two distinct clusters of tolerance indicators. On one hand, the CTRT factor captures the compulsive aspects of a preventable risk being tolerated, which is driven by irresistible urges for at-risk publics to take the risky behavior even if the risk-taking action is against their conscious wishes for personal health and well-being. On the other hand, the IRRP factor captures the inertial aspects of a preventable risk being tolerated, which is derived as a tendency to do nothing or unchanged existing risky behaviors, in which intentionally ignoring health messages or being indifferent to what these messages advocate are predominant manifestations. These two factors conceptually represent two opposite forces (equally powerful) that drive at-risk publics' willingness to overcome a risk or not.

Compulsive Type of Risk Tolerance (CTRT). The eight-item CTRT subscale measures individuals' self-reported degree of unwillingness to refrain from risky behaviors even if they know the consequences of not following recommended actions, which can be indicated by:

1. "I did it anyways, even though I knew it was an unhealthy choice";

2. "I know that what I chose is not a smart decision, and it is not healthy, but I had to pursue it";

3. "There is a risk in my choice, but I am willing to take that risk, even though it is not really good for myself"; 
4. "Even though I know the risk of doing what I do, I would still do it"; "Even though I know what I do is bad, I cannot give it up";

5. "I know what I am doing is bad and harmful, but I do not take actions to change";

6. "I choose to indulge despite knowing this choice is bad for me"; and

7. "When I receive the health message to pursue the recommended behavior, I willingly take the risk and tell myself that 'I will eventually do that."'

Inertial Type of Risk Tolerance (IRRP). The five-item IRRP subscale focuses on gauging individuals' self-reported level of indifference toward or intentionally ignoring health messages advocating for behavioral changes, which can be observed via:

1. "I ignore the risks that are described in the health messages";

2. "I did not really care that much about the effects of risks I am taking";

3. "If I read the recommended health message, I would feel disinterested, because I know I will not modify my behavior";

4. "If I read the recommended health message, I would feel insensitive, because I know I will not modify my behavior"; and

5. "I am going to choose this less healthy behavior regardless."

Noting that there are several additional concepts (e.g., interest, sensitivity, etc.) emerged as potential sub-concept to be further untangled and examined as either another layer of risk tolerance or identified as potential determinants that are particularly influential in forming an inertial type of risk tolerance.

These two factors contribute significantly to the conceptual and operational definitions of risk tolerance and how it differs from existing similar concepts, such as risk taking and risk acceptance. It confirms the core of our conceptualization of individual 
risk tolerance of preventable health risk as degree of unwillingness to overcome a preventable risk that threatens at-risk publics' own health, safety, and/or well-being. Risk tolerance, according to our study, is found to manifest in different forms of individual behaviors: (a) sustaining risky behaviors, (b) ignoring risk prevention recommendation, (c) co-existence of both (a) and (b). These observations seem to imply that at-risk publics' decision on whether to tolerate a preventable risk (or not) can determine whether (and if so, to what degree) certain risky behavior change is either enabled or inhibited at individual level.

\section{Implications for Risk Communication Practice}

For risk communication practitioners, with the role of selecting the most appropriate channel and design the most effective content to reach out to at-risk publics with accurate information (Park \& Avery, 2018; Park et al., 2019), evidence-based insights on the level of risk tolerance among specific publics toward a given risk issue have significant implications for more effective tailoring of risk communication messages for different health risk types. For example, when practitioners know, or are able to predict, which group of individuals might have higher or lower risk tolerance level toward a given health risk, they can plan more strategically in terms of which message characters should be used in order to overcome psychological barriers that create blockages that reduce the effects of health persuasion. With its established validity and stability, the risk tolerance scale is now ready to be used by practitioners for gauging at-risk publics' level of unwillingness to overcome a preventable risk with a relatively short list of items.

The risk tolerance scale developed and tested in this study offers a psychometric tool that can be utilized by practitioners in capturing the multiple facets of individuals' unwillingness to change risky behavior, which can be useful to track and predict at-risk publics' risk tolerance in order to develop the most effective health communication campaigns. Additionally, risk tolerance can be measured either as a trait of at-risk publics, to be gauged before risk messages are crafted, or as a state-based measure used to track at-risk publics' responses (or overtime response changes) 
to risk messages. Being able to measure risk tolerance, risk communication professionals' capacity to draw insights from behavioral research is expanded, which allows them to further design counter-messages that will help break down the risk-tolerance based barrier, particularly at a local level (Novak et al., 2019), thus increasing at-risk publics' willingness to follow the recommended preventive or protective actions and modify their risky behaviors accordingly (Avery, 2019; Reynolds \& Seeger, 2005).

\section{Limitations and Future Directions}

As the first study to develop a multi-item scale to specifically measure how individuals tolerate preventable and individually controllable health risks, this study advanced the explication of risk tolerance in the context of risk communication. However, it has several limitations that need to be addressed by future research.

First, some of our fit indices could be considered as a mediocre fit. For instance, our RMSEA is .09, and the recommendation for RMSEA cut-off points have been reduced in recent publications (Hooper et al., 2008; Hu \& Bentler, 1999; Steiger, 2007). However, MacCallum and his colleagues (1996) acknowledged RMSEA in the range of 0.05 and 0.10 as an indication of good fit. One of the reasons why our RMSEA could not be lower than .o9 can be based on the lack of normality of our data (Curran et al., 1996).

Second, although the conceptualization of risk tolerance posited by this study can be applied to both individual health risk and disaster risk types (Brady, 2012), the current scale itself is developed in the context of individual health risk. Since it was purposefully developed for a wide spectrum of individual health risks, how it may apply to measuring individuals' risk tolerance of a given risk in a specific context is one of the next steps to be taken by risk scholars. Furthermore, it is unknown whether the scale might apply to disaster risk type over which individuals have no or little control (Brady, 2012). In addition, whether the two clusters of risk-tolerating behaviors (i.e., risk taking despite knowing the consequences versus indifference to health messages) will emerge in disaster risk communication is yet to be further examined. Nevertheless, we posit that, some, if not all, items might be applied in the 
context of natural disasters (such as earthquakes and hurricanes) and/or manmade disasters (such as terrorist attacks), while new items or updated factor-structure might emerge from studies in disaster-specific contexts. Additionally, this study's scope is within the sphere of a layperson's risk perception and potential risk reaction (e.g., to take or not to take risk prevention as recommended by experts and/or government health authorities). To complete the picture and include all key players in tackling the challenge of preventable health risks, the risk tolerance concept and the current scale need to be further refined and expanded toward an advanced understanding of how medical experts and public health practitioners may use it to assess at-risk publics' risk tolerance and overcome it by motivating more preventive behaviors.

Third, future studies can help improve the external validity of the risk tolerance survey. We used the term "at-risk publics" to refer to any individuals threatened by any risk concerning their well-being. Although we sampled from the general U.S. population, each individual participant is "at-risk" of the threat caused by the focal health risk they were instructed to identify and focus on throughout the survey. Specifically, the survey instruction of the study asked participants to think of a health issue based on the three criteria (i.e., the issue is concerning to them, they are aware of ways to overcome this risk by modifying their behavior, and they choose to tolerate the risk regardless). However, our survey instrument did not measure level of concern, which might have created variances in how participants perceived each health risk on their mind and how they chose to tolerate it. To further test the scale, two additional individual characteristic based variables that need to be taken into consideration in future risk tolerance studies are: (1) at-risk publics' self-efficacy in modifying their risky behavior, as suggested by the social cognitive theory (Bandura, n.d.) and (2) their level of trust of certain health organizations who disseminate health information (e.g., the Centers for Disease Control and Prevention $[\mathrm{CDC}]$ ), which is built through continuous emotional involvement (Engdahl \& Lidskog, 2014) and may trigger individuals to decrease their risk tolerance and quickly modify their behavior when facing an acute risk or a health emergency. Both self-efficacy and trust can function as antecedents or covariates 
that lead to or help explain varied individual tolerance of a preventable health risk.

Fourth, this study only focuses on one concept, risk tolerance. Further predictive, discriminant, and convergent validity analyses are needed to examine to what degree and in what ways risk tolerance is different from other concepts (e.g., risk taking and risk acceptance), not only conceptually but empirically in predicting and/or explaining risk outcomes. How individuals' decisions on whether to tolerate a preventable risk (or not) might determine whether (and if so, to what degree) certain risky behavior change is either enabled or prohibited at an individual level needs to be examined in future multivariate studies. On one hand, the current risk tolerance scale can be used as one of the dependent measures (as outcome variables, mediator, or moderator) in studying the effectiveness of risk communication and how risk tolerance is related to other risk-tendency related concepts, such as risk desensitization, message fatigue, and social comparison theory. On the other hand, the concept of risk tolerance can be measured directly and applied to studying other preventable risks in not only individual health but also in environmental health (e.g., air pollution) and vaccine communication (e.g., flu vaccination hesitancy) as an antecedent or covariate of outcome variables essential to these risk domains.

Last but not least, the current conceptualization and measurement of risk tolerance apply solely on individuals who themselves are confronted by a risk that threatens their own health and well-being, which may not apply to individuals who are decision makers for others' health (including tolerating risk prevention for the benefit of others). In the example of getting HPV as a health risk to teenagers, parents (not teens themselves) are directly making decisions for their children's HPV vaccination: If parents are postponing getting an HPV vaccine for their children, then the parents' risk tolerance should be measured as they are the ones making the decision to tolerate the risk of their child getting HPV. Future studies in such preventable health risks should use or modify the current risk tolerance scale to gauge not only the tolerance of at-risk publics' but also that of the decision makers of at-risk individuals regarding certain risks. 
In summary, this study is a significant step toward defining risk tolerance in risk communication and developing a valid and reliable measurement of at-risk publics' tolerance of individual health risks. The insights from this study reflect Liu et al.s (2016) argument that knowing how much inherent uncertainty publics perceive in risk communication serves as key for practitioners to communicate effectively to at-risk publics, which also paves the way for future studies to continue unearthing and overcoming risk communication barriers in order to enhance risk message effectiveness.

\section{ORCID}

Hyoyeun Jun (1) https://orcid.org/oooo-0002-5283-9831

Yan Jin (1) https://orcid.org/0ooo-00o3-4228-5529

\section{References}

Aakko, E. (2004). Risk communication, risk perception, and public health. Wisconsin Medical Journal, 103(1), 25-28.

Abdi, H., \& Williams, L. J. (2010). Principal component analysis. Wiley Interdisciplinary Reviews: Computational Statistics, 2(4), 433-459. https://doi.org/10.1002/wics.101

Avery, E. J. (2019). The effects of community size, control over agenda, and contextual variables on Zika virus preparation of public information officers at local public health departments. Journal of International Crisis and Risk Communication Research, 2(1), https://doi.org/10.30658/jicrcr.2.1.5

Baird, B. N. (1986). Tolerance for environmental health risks: The influence of knowledge, benefits, voluntariness, and environmental attitudes. Risk Analysis, 6(4), 425-435. https://doi. org/10.1111/j.1539-6924.1986.tboo955.X

Baird B. N., Earle T. C., \& Cvetkovich G. (1987) Public judgment of an environmental health hazard: Two studies of the ASARCO smelter. In L. B. Lave (Ed.), Risk Assessment and Management. Advances in Risk Analysis, vol. 5 (pp. 383-398). Springer. https://doi.org/10.1007/978-1-4757-6443-7_38 
Bandura, A. (n.d.). Self-efficacy. Encyclopedia of Psychological Assessment. https://doi.org/10.4135/9780857025753.n178

Bauer, R. A. (1960). Consumer behavior as risk taking. In M. J. Baker (Ed.), Marketing: Critical Perspectives on Business and Management (pp. 384-398). Taylor \& Francis.

Bean, H., Sutton, J., Liu, B. F., Madden, S., Wood, M. M., \& Mileti, D. S. (2015). The study of mobile public warning messages: A research review and agenda. Review of Communication, 15(1), 6o-8o. https://doi.org/10.1080/15358593.2015.1014402

Bennett, P. (1999). Understanding responses to risk: Some basic findings. In P. Bennett \& K. Calman (Eds.), Risk Communication and Public Health (pp. 3-19). Oxford University Press. https:// doi.org/10.1093/acprof:0so/9780199562848.003.01

Brady, J. T. (2012). Health risk perceptions across time in the USA. Journal of Risk Research, 15(6), 547-563. https://doi.org/10.10 8o/13669877.2011.643476

Chen, Y. (2018). The roles of prevention messages, risk perception, and benefit perception in predicting binge drinking among college students. Health Communication, 33(7), 877-886. https:// doi.org/10.1080/10410236.2017.1321161

Clark, L. A., \& Watson, D. (1995). Constructing validity: Basic issues in objective scale development. Psychological Assessment, 7(3), 309-319. https://doi.org/10.1037/1040-3590.7.3.309

Comrey, A. L. (1988). Factor-analytic methods of scale development in personality and clinical psychology. Journal of Consulting and Clinical Psychology, 56, 754-761. https://doi. org/10.1037/0022-006x.56.5.754

Coombs, W. T., Holladay, S. J., \& Tachkova, E. (2019). In B. R. Brunner (Ed.), Public Relations Theory: Application and Understanding Crisis Communication, Risk Communication, and Issues Management. Public Relations Theory: Application and Understanding. John Wiley \& Sons.

Cornia, A., Dressel, K., \& Pfeil, P. (2016). Risk cultures and dominant approaches towards disasters in seven European countries. Journal of Risk Research, 19(3), 288-304. https://doi.org/ 10.1080/13669877.2014.961520 
Covello, V., \& Sandman, P. M. (2001). Risk communication: Evolution and revolution. Solutions to an Environment in Peril, 164-178.

Covello, V. T. (1983). The perception of technological risks: A literature review. Technological Forecasting and Social Change, 23(4), 285-297. https://doi.org/10.1016/0040-1625(83)90032-X

Covello, V. T. (2008). Strategies for overcoming challenges to effective risk communication. In R. L. Heath \& D. O'Hair (Eds.), Handbook of Risk and Crisis Communication (pp. 143-167). Taylor \& Francis Ltd. https://doi.org/10.4324/9780203891629 Covello, V. T., Von Winterfeldt, D., \& Slovic, P. (1988). Risk communication. In Carcinogen Risk Assessment (pp. 193-207). Springer. https://doi.org/10.1007/978-1-4684-5484-0_15

Cox, D. F., \& Rich, S. U. (1964). Perceived risk and consumer decision-making-The case of telephone shopping. Journal of Marketing Research, 1(4), 32-39. https://doi. org/10.2307/3150375

Curran, P. J., West, S. G., \& Finch, J. F. (1996). The robustness of test statistics to nonnormality and specification error in confirmatory factor analysis. Psychological Methods, 1(1), 16-29. https://doi.org/10.1037/1082-989x.1.1.16

Dowling, G. R. (1986). Perceived risk: The concept and its measurement. Psychology \& Marketing, 3(3), 193-210. https://doi. org/10.1002/mar.4220030307

Eastin, M. S., Kahlor, L. A., Liang, M.-C., \& Ghannam, N. A. (2015). Information-seeking as precaution behavior: Exploring the role of decision-making stages. Human Communication, 41, 603-621. https://doi.org/10.1111/hcre.12062

Engdahl, E., \& Lidskog, R. (2014). Risk, communication and trust: Towards an emotional understanding of trust. Public Understanding of Science, 23(6), 703-717. https://doi. org/10.1177/0963662512460953

Fama, E. F. (1980). Agency problems and the theory of the firm. Journal of Political Economy, 88(2), 288-307. https://doi. org/10.1017/cbo9780511817410.022

Fell, R. (1994). Landslide risk assessment and acceptable risk. Canadian Geotechnical Journal, 31(2), 261-272. https://doi. org/10.1139/t94-031 
Ferguson, M. A., Valenti, J. M., \& Melwani, G. (1991). Communicating with risk takers: A public relations perspective. Journal of Public Relations Research, 3(1-4), 195-224. https://doi.org/10.1207/s1532754xjprro301-4_10

Fischhoff, B., Slovic, P., Lichtenstein, S., Read, S., \& Combs, B. (1978). How safe is safe enough? A psychometric study of attitudes towards technological risks and benefits. Policy Sciences, 9(2), 127-152. https://doi.org/10.1007/bfoo143739

Fishbein, M., \& Ajzen, I. (1975). Belief, attitude, intention and behavior. Addison-Wesley.

Gaube, S., Lermer, E., \& Fischer, P. (2019). The concept of risk perception in health-related behavior theory and behavior change. In M. Raue, B. Streicher, \& E. Lermer (Eds.), Perceived Safety Risk Engineering. Springer, Cham. https://doi. org/10.1007/978-3-030-11456-5_7

Griffin, R. J., Dunwoody, S., \& Neuwirth, K. (1999). Proposed model of the relationship of risk information seeking and processing to the development of preventive behaviors. Environmental Research, 8o(2), 230-245. https://doi. org/10.1006/enrs.1998.3940

Groothuis, P. A., \& Miller, G. (1994). Locating hazardous waste facilities: The influence of NIMBY beliefs. American Journal of Economics and Sociology, 53(3), 335-346. https://doi. org/10.1111/j.1536-7150.1994.tbo2603.X

Hallahan, K., Holtzhausen, D., Van Ruler, B., Verčič, D., \& Sriramesh, K. (2007). Defining strategic communication. International Journal of Strategic Communication, 1(1), 3-35. https://doi.org/10.1080/15531180701285244

Harries, T., \& Penning-Rowsell, E. (2011). Victim pressure, institutional inertia and climate change adaptation: The case of flood risk. Global Environmental Change, 21(1), 188-197. https:// doi.org/10.1016/j.gloenvcha.2010.09.002

Haukenes, A. (2004). Perceived health risks and perceptions of expert consensus in modern food society. Journal of Risk Research, 7(7-8), 759-774. https://doi.org/10.1080/ 13669870210166194 
Heath, R. L., \& Abel, D. D. (1996). Proactive response to citizen risk concerns: Increasing citizens' knowledge of emergency response practices. Journal of Public Relations Research, 8(3), 151-171. https://doi.org/10.1207/s1532754xjprro803_02

Heath, R. L., Lee, J., \& Lemon, L. L. (2019). Narratives of risk communication: Nudging community residents to shelterin-place. Public Relations Review, 45(1), 128-137. https://doi. org/10.1016/j.pubrev.2018.12.004

Heath, R. L., Lee, J., \& Ni, L. (2009). Crisis and risk approaches to emergency management planning and communication: The role of similarity and sensitivity. Journal of Public Relations Research, 21(2), 123-141. https://doi.org/10.1080/1062726080 2557415

Heath, R. L., Liao, S. H., \& Douglas, W. (1995). Effects of perceived economic harms and benefits on issue involvement, use of information sources, and actions: A study in risk communication. Journal of Public Relations Research, 7(2), 89-109. https:// doi.org/10.1207/s1532754xjprro702_01

Heath, R. L., \& O'Hair, D. (Eds.). (2009). Handbook of risk and crisis communication. Routledge.

Heath, R. L., \& Palenchar, M. (2000). Community relations and risk communication: A longitudinal study of the impact of emergency response messages. Journal of Public Relations Research, 12(2), 131-161. https://doi.org/10.1207/s1532754xjprr1202_1 Heath, R. L., Seshadri, S., \& Lee, J. (1998). Risk communication: A two-community analysis of proximity, dread, trust, involvement, uncertainty, openness/accessibility, and knowledge on support/opposition toward chemical companies. Journal of Public Relations Research, 10(1), 35-56. https://doi. org/10.1207/s1532754xjprr1001_02

Hendrickson, A. E., \& White, P. O. (1964). PROMAX: A quick method for rotation to oblique simple structure. British Journal of Statistical Psychology, 17, 65-70. https://doi. org/10.1111/j.2044-8317.1964.tboo244.x

Hooper, D., Coughlan, J., \& Mullen, M. R. (2008). Structural equation modelling: Guidelines for determining model fit. Electronic Journal of Business Research Methods, 6(1), 53-60. 
Hu, L. T., \& Bentler, P. M. (1999). Cutoff criteria for fit indexes in covariance structure analysis: Conventional criteria versus new alternatives. Structural Equation Modeling: A Multidisciplinary Journal, 6(1), 1-55. https://doi.org/10.1080/1070551990954 0118

Hunter, P. R., \& Fewtrell, L. (2001). Acceptable risk. World Health Organization (Ed.) Water Quality: Guidelines, Standards and Health. Risk assessment and management for water-related infectious disease (pp. 207-227). IWA Publishing. https://doi. org/10.2166/9781780405889

Irwin, C. E. (1993). Adolescence and risk taking: How are they related? In N. J. Bell \& R.W. Bell (Eds.), Adolescent Risk Taking (pp. 7-28). Sage Publications.

Janoske, M. L., Liu, B. F., \& Madden, S. (2013). Congress report: Experts' recommendations on enacting best practices in risk and crisis communication. Journal of Contingencies and Crisis Management, 21(4), 231-235. https://doi.org/10.1111/14685973.12031

Kahlor, L. (2010). Prism: A planned risk information seeking model. Health Communication, 25(4), 345-356. https://doi. org/10.1080/10410231003775172

Kaiser, H. F., \& Rice, J. (1974). Little Jiffy, Mark IV. Educational and Psychological Measurement, 34(1), 111-117. https://doi. org/10.1177/001316447403400115

Kasperson, R. E., \& Palmlund, I. (1989). Evaluating risk communication. In V. T. Covello, D. B. McCallum, \& M. T. Pavlova (Eds.), Effective Risk Communication: The Role and Responsibility of Government and Nongovernment Organizations (pp. 143-158), Springer. https://doi.org/10.1007/978-1-4613-1569-8_21

Kentel, E., \& Aral, M. M. (2007). Risk tolerance measure for decision-making in fuzzy analysis: A health risk assessment perspective. Stochastic Environmental Research and Risk Assessment, 21(4), 405-417. https://doi.org/10.1007/s00477006-0073-2

Krewski, D., Turner, M. C., Lemyre, L., \& Lee, J. E. C. (2012). Expert vs. public perception of population health risks in Canada. Journal of Risk Research, 15(6), 601-625. https://doi. org/10.1080/13669877.2011.649297 
Kwak, Y. H., \& LaPlace, K. S. (2005). Examining risk tolerance in project-driven organization. Technovation, 25(6), 691-695. https://doi.org/10.1016/j.technovation.2003.09.003

Lindlof, T. R., \& Taylor, B. C. (2017). Qualitative communication research methods. SAGE Publications.

Liu, B. F., Bartz, L., \& Duke, N. (2016). Communicating crisis uncertainty: A review of the knowledge gaps. Public Relations Review, 42(3), 479-487. https://doi.org/10.1016/j. pubrev.2016.03.003

Liu, B. F., \& Pompper, D. (2012). The crisis with no name: Defining the interplay of culture, ethnicity, and race on organizational issues and media outcomes. Journal of Applied Communication Research, 40(2), 127-146. https://doi.org/10.1080/00909882.2 012.654499

Liu, B. F., Wood, M. M., Egnoto, M., Bean, H., Sutton, J., Mileti, D. S., \& Madden, S. (2017). Is a picture worth a thousand words? The effects of maps and warning messages on how publics respond to disaster information. Public Relations Review, 43(3), 493-506. https://doi.org/10.1016/j.pubrev.2017.04.004 MacCallum, R. C., Browne, M. W., \& Sugawara, H. M. (1996). Power analysis and determination of sample size for covariance structure modeling. Psychological Methods, 1(2), 130149. https://doi.org/10.1037/1082-989x.1.2.130

Meyers, L. S., Gamst, G., \& Guarino, A. J. (2013). Applied multivariate research (2nd ed.). In L. S. Meyers, G. Gamst, \& A. J. Guarino (Eds.), Sage Publications.

Nathan, K., Heath, R. L., \& Douglas, W. (1992). Tolerance for potential environmental health risks: The influence of knowledge, benefits, control, involvement, and uncertainty. Journal of Public Relations Research, 4(4), 235-258. https://doi. org/10.1207/s1532754xjprro404_4

Novak, J. M., Day, A. M., Sopory, P., Wilkins, L., Padgett, D. R., Eckert, S., Noyes, J., Allen, T., Alexander, N., Vanderford, M., \& Gamhewage, G. (2019). Engaging communities in emergency risk and crisis communication: Mixed-method systematic review and evidence synthesis. Journal of International 
Crisis and Risk Communication Research, 2(1), 61-96. https:// doi.org/10.30658/jicrcr.2.1.4

Office of Government Commerce (OGC). (2001). A8: Managing Risk. Crown. http://www.ogc.gov.uk

Paek, H. J., \& Hove, T. (2017). Risk perceptions and risk characteristics. In Oxford Research Encyclopedia of Communication. https://doi.org/10.1093/acrefore/9780190228613.013.283

Park, S., \& Avery, E. J. (2018). Effects of media channel, crisis type and demographics on audience intent to follow instructing information during crisis. Journal of Contingencies and Crisis Management, 26(1), 69-78. https://doi.org/10.1111/14685973.12137

Park, S., Boatwright, B., \& Avery, E. J. (2019). Information channel preference in health crisis: Exploring the roles of perceived risk, preparedness, knowledge, and intent to follow directives. Public Relations Review, 45(5), 101794. https://doi. org/10.1016/j.pubrev.2019.05.015

Peter, J. P., \& Tarpey Sr., L. X. (1975). A comparative analysis of three consumer decision strategies. Journal of Consumer Research, 2(1), 29-37. https://doi.org/10.1086/208613

Ramon, S. (2009). Risk avoidance and risk taking in mental health social work. In D. Murphy \& D. Longo (Eds.), Encyclopedia of Psychology of Decision Making (pp. 261-277). Nova Science Publishers.

Reynolds, B., \& Seeger, M. (2005). Crisis and emergency risk communication as an integrative model. Journal of Health Communication, 10(1), 43-55. https://doi. org/10.1080/10810730590904571

Richman, M. B. (1988). A cautionary note concerning a commonly applied eigenanalysis procedure. Tellus $B, 40(1), 50-58$. https://doi.org/10.1111/j.1600-0889.1988.tboo212.X

Rook, K. S., Thuras, P. D., \& Lewis, M. A. (1990). Social control, health risk taking, and psychological distress among the elderly. Psychology and Aging, 5(3), 327-334. https://doi. org/10.1037/0882-7974.5.3.327 
Rudisill, C. (2013). How do we handle new health risks? Risk perception, optimism, and behaviors regarding $\mathrm{H}_{1} \mathrm{~N}_{1}$ virus. Journal of Risk Research, 16(8), 959-980. https://doi.org/10.10 8o/13669877.2012.761271

Sjöberg, L., \& Drottz-Sjöberg, B. M. (2001). Fairness, risk and risk tolerance in the siting of a nuclear waste repository. Journal of Risk Research, 4(1), 75-101. https://doi. org/10.1080/136698701456040

Slovic, P. (1987). Perception of risk. Science, 236(4799), 280-285. https://doi.org/10.1126/science.3563507

Slovic, P. (1992). Perception of risk: Reflections on the psychometric paradigm. In S. Krimsky \& D. Golding (Eds.), Social Theories of Risk (pp. 117-152). Praeger Publisher.

Slovic, P. (2016). Understanding perceived risk: 1978-2015. Environment: Science and Policy for Sustainable Development, 58(1), 25-29. https://doi.org/10.1080/00139157.2016.1112169 Slovic, P., Kraus, N. N., Lappe, H., Letzel, H., \& Malmfors, T. (1989). Risk perception of prescription drugs: Report on a survey in Sweden. In B. Horisberger \& R. Dinkel (Eds.), The Perception and Management of Drug Safety Risks (pp. 90-111). SpringerVerlag Berlin Heidelberg. https://doi.org/10.1007/978-3-64274272-9_12

Starr, C. (1969). Social benefit versus technological risk. Science, 165(3899), 1232-1238. https://doi.org/10.1126/science.165. 3899.1232

Steiger, J. H. (2007). Understanding the limitations of global fit assessment in structural equation modeling. Personality and Individual Differences, 42(5), 893-898. https://doi. org/10.1016/j.paid.2006.09.017

Tabachnick, B. G., Fidell, L. S., \& Ullman, J. B. (2007). Using multivariate statistics (Vol. 5). Pearson.

Taylor, J. W. (1974). The role of risk in consumer behavior: A comprehensive and operational theory of risk taking in consumer behavior. Journal of Marketing, 38(2), 54-60. https:// doi.org/10.1177/002224297403800211 
Tchiehe, D. N., \& Gauthier, F. (2017). Classification of risk acceptability and risk tolerability factors in occupational health and safety. Safety Science, 92, 138-147. https://doi.org/10.1016/j. ssci.2016.10.003

U.S. Department of Health and Human Services. (2000). Public Health Service: Healthy People 2, ooo, National Health Promotion and Disease Prevention Objectives. DHHS Publication No. (PHS) 9 1-502 13 (pp. 20-22).

Venette, S. (2008). Risk as an inherent element in the study of crisis communication. Southern Communication Journal, 73(3), 197-210. https://doi.org/10.1080/10417940802219686

Venette, S. J. (2003). Risk communication in a high reliability organization. UMI Proquest Information and Learning.

Vogt, W. P. (1997). Tolerance \& education: Learning to live with diversity and difference. Sage Publications.

Waymer, D., \& Heath, R. L. (2015). Critical race and public relations: The case of environmental racism and risk bearer agency. In J. L'Etang, D. McKie, N. Snow, \& J. Xifra (Eds.), The Routledge Handbook of Critical Public Relations (pp. 313-326). Routledge.

Weber, E. U., Blais, A., \& Betz, N. (2002). A domain-specific riskattitude scale: Measuring risk perceptions and risk behaviors. Journal of Behavioral Decision-Making, 15, 263-290. https:// doi.org/10.1002/bdm.414 


\section{Appendix A \\ Initial Item Pool for Risk Tolerance Scale Development}

(1) I understand that there is higher risk if I keep doing this and not following the recommended behavior, but I had to do this anyways;

(2) I did it anyways, even though I knew it is an unhealthy choice;

(3) I keep putting it off to follow that recommended behavior;

(4) I know that what I chose is not a smart decision, and it is not healthy, but I had to pursue it;

(5) I thought I could take only small responsibility while I was not following the recommended behavior, even though I knew it's obviously bad for me;

(6) I kept meaning to pursue the recommended healthy behavior, but I kept putting it off;

(7) I was aware that there was a real possibility that I was going to be less healthy, if I kept putting it off to behave healthy;

(8) There is a risk in my choice, but I am willing to take that risk, even though it is not really good for myself;

(9) I feel like I need to lose the healthiest choice, as a pay-off, to achieve my goal;

(10) I do not mind taking the risk of not following the recommended behavior;

(11) Even though I know the risk of doing what I do, I would still do it;

(12) I just ignore the recommended healthier behavior, because I already know that I am not going to do it;

(13) I just ignore the recommended healthier behavior, because it does not affect me;

(14) When I receive the health message to pursue the recommended behavior, I willingly take the risk and tell myself that "I will eventually do that";

(15) I know that I will eventually follow the advice, but just not right now, where deep down I know that I probably will not follow the advice;

(16) When I read about the recommended behavior that I am supposed to follow, I become defensive;

(17) When I read about the recommended behavior that I am supposed to follow, I blame the publisher of the article to doubt if it is the right source;

(18) When I read about the recommended behavior that I am supposed to follow, I look for evidence for the other side to back up my behavior;

(19) I feel like I am still avoiding bigger risk by choosing what I do, even though it is not the healthiest behavior; 
(20) The risks that I do not mind tolerating as much are those that I see as less risky;

(21) I tune out for the risks I am taking;

(22) I take the less healthy choice, because I feel like I need it;

(23) I am not worried about having higher risks just because I did not take the recommended behavior;

(24) Even though I know what I do is bad, I cannot give it up;

(25) I know what I am doing is bad and harmful, but I do not take actions to change;

(26) Whenever I have sickness, I do not take time to go to the doctor, because I know I will get over it eventually;

(27) Taking time to go to the doctor just is not a priority, when I feel sick;

(28) I often sacrifice my own health for the other choices I am making;

(29) I ignore the risks that are described in the health messages;

(30) I ignore my doctor's advice;

(31) I did not really care that much about the effects of risks I am taking;

(32) If I read the recommended health message, I would feel disinterested, because I know I will not modify my behavior;

(33) If I read the recommended health message, I would feel insensitive, because I know I will not modify my behavior;

(34) If I read the recommended health message, I would feel insensitive, because I know I will not modify my behavior;

(35) Even though I know there are high safety risks, I would still take my current behavioral choice;

(36) I have got nothing to do about changing my behavior into a healthier way;

(37) I am still going to choose what I have done so far, because I am used to it;

(38) I am more focused on how much benefits I can get from my choice than the negative health risks;

(39) I do this less healthy behavior, even though it is not good for me;

(40) I am going to choose this less healthy behavior regardless;

(41) Sometimes, I just think I will deal with the consequences of these health risks later;

(42) Healthier choices are pushed out of the order of priority;

(43) Even though I am aware of the health risks of the choice I pursue, I chose to take the benefits of my choice over other healthier choices; 
(44) After considering the benefits and risks of my choices, I decide that the benefits outweigh the risks;

(45) I choose to indulge despite knowing this choice is bad for me;

(46) I did disregard the messages from the health campaigns recommending me to change my choices;

(47) I resist pursuing healthier choices for myself;

(48) When I choose my decision, I take my less healthy choice and weigh it against the recommendation;

(49) I usually behave in healthy way, but at times, I tend to take less healthier choices that I know they are not healthy for me;

(50) I ignored the health messages and decided to keep what I have been doing;

(51) I knew the risks of my choices, but the benefits of my choices spurred me on;

(52) I know that there are less risky choices for my health, but I ignore them purely for benefits' sake;

(53) I do understand that what I have been choosing contains a risk, but I do not think I do it too often for it to be a concern. 


\section{Appendix B \\ Recommended Individual Health Risk Tolerance Scale}

Instruction: Please indicate your level of agreement or disagreement with each of the following statements, which describe what you do (or not do) about [ $a$ preventable health risk you yourself are currently facing or are likely to face in the future]. Each item is measured using a 7-point Likert-type scale ranging from " 1 = Strongly Disagree" to " 7 = Strongly Agree."

\section{Subscale 1: Compulsive Tendency for Risk Taking (CTRT)}

- I did it anyways, even though I knew it was an unhealthy choice.

- I know that what I chose is not a smart decision, and it is not healthy, but I had to pursue it.

- There is a risk in my choice, but I am willing to take that risk, even though it is not really good for myself.

- Even though I know the risk of doing what I do, I would still do it.

- Even though I know what I do is bad, I cannot give it up.

- I know what I am doing is bad and harmful, but I do not take actions to change.

- I choose to indulge despite knowing this choice is bad for me.

- When I receive the health message to pursue the recommended behavior, I willingly take the risk and tell myself that "I will eventually do that."

\section{Subscale 2: Inertial Resistance to Risk Prevention (IRRP)}

- I ignore the risks that are described in the health messages.

- I did not really care that much about the effects of risks I am taking.

- If I read the recommended health message, I would feel disinterested, because I know I will not modify my behavior.

- If I read the recommended health message, I would feel insensitive, because I know I will not modify my behavior.

- I am going to choose this less healthy behavior regardless. 

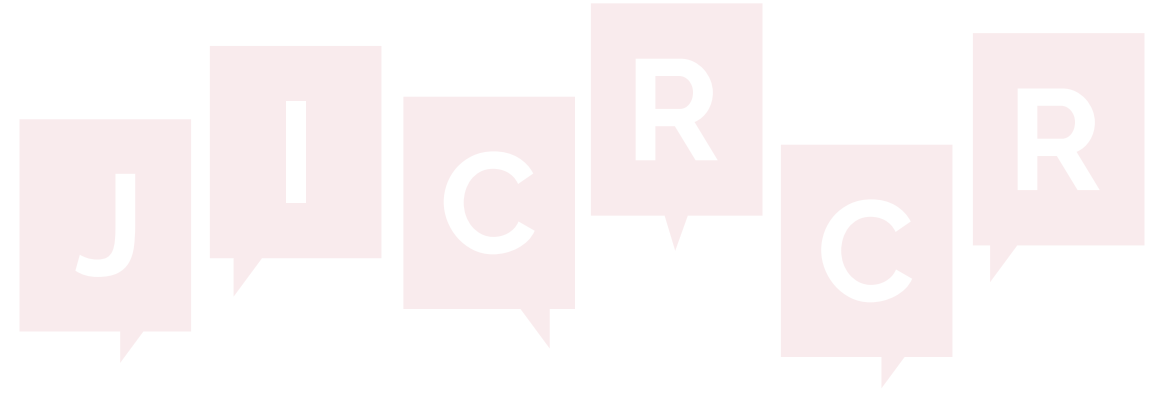